ences go some way towards explaining why the A.G.R. has seemed expensive in comparison with Amcrican designs. In generating costs, the appraisal made much of the fact that the A.G.R. could be re-fuelled while on-load, giving it a big advantage on "availability adjustment". This advantage, Mr. Burn suggests, is a trivial one, and hardly worth the importance the appraisal put on it.

Comparisons of this sort are particularly hard to make, as Mr. Burn shows in an appendix devoted to reconciling the cost estimates for Nine Mile Point nuclear station in the U.S., ordered from G.E. a few weeks before Oyster Creek, and costing far more $(0.57 \mathrm{~d} / \mathrm{kWh}$ compared with $0.34 \mathrm{~d} / \mathrm{kWh})$. If differences of this order can occur in the same country, it is perhaps not surprising that comparable discrepancies can occur across the Atlantic. A more charitable author might see an explanation in this, but $\mathrm{Mr}$. Burn does not.

\section{Britain in Space}

IF European space research programmes sometimes seem more substantial than they are, it is probably because of a tendency to announce the imminent launching of satellites several times before they actually get off the ground. One satellite can seem like three. Latest victim of this largely unavoidable exercise is U.K. 3, the first all-British satellite, the long-awaited departure of which from NASA's Western Test Range in California is now promised for May 5.

U.K. 3, planned for four years and built by British Aircraft Corporation and G.E.C. Electronics, Ltd., is wholly British except for some American electronic components chosen because of their proved reliability. Weighing $198 \mathrm{lb} .(85 \cdot 2 \mathrm{~kg})$ and built at a cost of $£ 1 \frac{1}{4}$ million, the satellite will be launched into an almost circular orbit at an inclination of $80^{\circ}$ and at a height of 340 miles $(550 \mathrm{~km})$. It will orbit the Earth every 95 minutes, at a speed of 17,000 m.p.h. The rocket used for the launch will be a four stage solid fuel Scout, and the orbit has been chosen so that the entire surface of the globe will have been traversed up to a latitude of $80^{\circ}$ at all times of the day by the end of the third month after launching. U.K. 3 will be tracked by the world-wide chain of NASA space tracking and data acquisition stations, and the Radio and Space Research Station. Information will be sent either direct from the satellite as it is collected, or by recording it on a continuous loop of magnetic tape and transmitting on command from the ground. In this way the information obtained during one complete orbit can be transmitted to any ground station in about two minutes.

The satellite carries five experiments. The Radio and Space Research Station is studying the distribution of terrestrial noise-mainly lightning discharges--over the surface of the Earth, as an aid in the design of radio communication circuits. The distribution of molccular oxygen in the high atmosphere will be investigated by the Meteorological Office, and radio signals below $20 \mathrm{kc} / \mathrm{s}$ by the University of Sheffield. An experiment designed by workers at Jodrell Bank will map large scale sources of noise in the galaxy, and the University of Birmingham is interested in the electron density and temperature in the plasma near the satellite. The experiments for this co-operative programme between the U.S. and the British Governments were chosen in consultation with NASA. If the launch should go wrong, there is a second satellite fully instrumented and ready to go, but if the satellite fails NASA clearly have no obligation to provide another launch vehicle. Further delays are unthinkable though, and the possibility has not been given serious thought.

\section{World Health}

THE director-general of the World Health Organization presents a somewhat gloomy picture of the progress of the work of WHO in the so-called developing countries (The Work of WHO: Annual Report of the DirectorGeneral to the World Health Organization and to the United Nations: Geneva, 1967). He draws attention to the widening gap separating the developing countries from the advanced countries, in the field of medicine as in other fields. In part, Dr. Candau puts this gap down to the inability or unwillingness of the advanced countries to provide sufficient resources for the programmes of the Organization. On the other hand, he hints that even if the money were forthcoming the difficulties would to a large extent remain. He speaks of "the absence of those well-established and realistic planning processes without which the optimum utilization of all available resources cannot be ensured". $\mathrm{He}$ goes on to warn that the disappointing headway made by the Organization in strengthening the basic national health services of developing countries will have an adverse effect on practically all the programmes of the Organization, particularly those directed at the control of communicable disease.

The warning is not an idle one. In the past five years a major epidemic of El Tor cholera has spread from Indonesia to reach the Soviet Union and Iraq. It was preceded by a rise in the frequency of sporadic infection, no doubt as a result of the growing pressure on the sanitary resources of the large cities of the endemic area. Given proper treatment (by saline infusion), most of the patients can be saved from death, but it is doubtful whether the resources exist to bring the treatment to all who will need it. These difficulties seem to epitomize the dangers Dr. Candau is talking about. No one would deny that WHO is doing valuable and essential work, often under daunting conditions, but the issue involved here cannot be resolved by goodwill alone. The financial and human resources have to be made available as a matter of urgency. Apart from cholera, other serious diseases are becoming more prevalent in many areas: prominent among these is poliomyelitis. What Dr. Candau seems to be worried about is that the work put in by the World Health Organization should not be vitiated by the effects of the growing impoverishment of the backward areas of the world.

On the credit side, Dr. Candau can point to a steady advance in the eradication of malaria over large parts of the world. The WHO malaria programmes affect nearly 900 million peoplc and satisfactory progress has been made in areas affecting some 700 million. In Africa, however, the advances have been far less spectacular and the report sounds a note of alarm about the slowness of the progress in some areas. Advances have also been made in dealing with yellow fever, dengue and various widespread parasitic disorders. One of the 